\title{
Custos da Saúde: Alguns Princípios
}

\author{
Health Costs: Basic Issues
}

Pedro Pita BARROS
Acta Med Port 2013 Sep-Oct;26(5):496-498

Palavras-chave: Custos de Cuidados de Saúde; Gastos em Saúde; Prestação de Cuidados de Saúde; Reforma dos Serviços de Saúde; Serviço Nacional de Saúde; Portugal.

Keywords: Delivery of Health Care; Health Care Costs; Health Care Reform; Health Expenditures; National Health Programs; Portugal.

\section{Custos, proteção na doença e seu valor}

Em momentos de dificuldade económica geral é natural que (re)nasça a discussão dos custos com a saúde. Em Portugal, a discussão recai na sustentabilidade financeira do Serviço Nacional de Saúde (SNS). A razão está na forma como a sociedade decidiu organizar a proteção aos cidadãos em caso de doença destes. O que se passa no SNS determina muito do que se gasta em saúde, seja diretamente, seja pelas próprias regras do SNS que obrigam a pagamentos complementares por parte dos cidadãos. Quando um cidadão paga uma parte do preço de um medicamento prescrito por um médico no âmbito da cobertura do Serviço Nacional de Saúde, essa despesa embora seja classificada como de agentes privados para agentes privados foi determinada por uma decisão pública, do SNS.

A discussão dos custos com a saúde passa inevitavelmente pelo funcionamento do SNS. ${ }^{1}$ A discussão sobre o SNS, por seu lado, tem que partir do entendimento de qual o seu objectivo. O objectivo de um agente do SNS pode ser diferente do objectivo da instituição onde está, que pode diferir do objectivo do sistema em si.

O SNS tem como objectivo primordial garantir proteção na doença a qualquer residente em Portugal, sem que tal possa ficar dependente da capacidade financeira individual, bem como promover a saúde da população. A forma como este objectivo é alcançado não está previamente determinado de modo inequívoco e rígido.

Se o problema de custos com a saúde é sobretudo um problema de despesa elevada, então a sua solução poderá passar por uma redução da proteção dada pelo SNS?

Se o objectivo for apenas conter custos, a resposta será afirmativa. Mas nesse caso está-se a perder o valor económico que a sociedade atribui a essa proteção. Este é um valor usualmente ignorado nas discussões sobre os custos do SNS.

Tomemos um exemplo simples. De acordo com a tabela de preços do SNS para intervenção cirúrgica em listas de espera, um transplante hepático tem um valor de 89288,56 euros, sendo que Portugal tem em média cerca de dois transplantes hepáticos por 100000 habitantes. Está cada residente em Portugal disposto a pagar cinco euros por ano para um fundo que pague essa despesa, isolando o cidadão das consequências financeiras? Sendo a resposta afirmativa, o valor atribuído à proteção na doença torna-se patente. Em cada 100000 pessoas seriam recolhidos 500000 euros, verba superior à necessária para cobrir as despesas com os dois transplantes que em média serão realizados nessa população.

O reduzir a cobertura do SNS, em termos de serviços e cuidados de saúde cobertos, tem então um custo económico, mesmo que não seja contabilizado da forma habitual e não seja somado aos restantes custos.

Nem todos os custos do SNS têm esta característica de elevado custo e necessidade absoluta. A intenção foi unicamente a de ilustrar o valor da proteção em condições de incerteza.

\section{Custos e a organização da prestação de cuidados de saúde}

Face à importância da proteção na doença que se pretende garantir, a definição da forma como é assegurado o acesso a cuidados de saúde necessários terá implicações potenciais em termos dos custos que será preciso financiar no âmbito dessa proteção financeira em caso de doença.

Optou-se, em Portugal, por ter uma prestação direta de cuidados de saúde pelo SNS, fazendo com que a eficiência deste seja um aspecto crucial para o que normalmente se designa por custos públicos com a saúde. Esta opção tem recebido apoio generalizado da população, e o financiamento por impostos parece ser o preferido dos portugueses. $^{2}$

Nas instituições do SNS que têm a missão de prestar cuidados de saúde, o objectivo não são os custos em si mesmos. O problema de gestão das organizações é, então, o de garantir os objectivos assistenciais com o menor custo de os alcançar.

1. Nova School of Business and Economics, INOVA. Universidade Nova de Lisboa. Lisboa. Portugal.

Recebido: 16 de Junho de 2013 - Aceite: 17 de Junho de 2013 | Copyright @ Ordem dos Médicos 2013 
O crescimento do orçamento do SNS transmite uma primeira visão da pressão que existe para a subida dos custos com cuidados de saúde. A própria recorrência de orçamentos rectificativos (fazendo com que a dotação final do SNS seja diferente da dotação inicial) fornece evidência dessa pressão.

O problema fundamental é então como conter o ritmo de crescimento das despesas com cuidados de saúde, dentro dos objectivos assistenciais e de proteção na doença pretendidos. Infelizmente, não se conhece uma regra mágica que permita resolver de modo rápido e eficaz este problema. A resposta envolverá múltiplos pequenos passos, simultâneos e que se reforcem.

Um dos aspectos centrais é o controlo dos custos com as novas tecnologias, nomeadamente na definição do que ser incluído nas opções terapêuticas do Serviço Nacional de Saúde. ${ }^{3}$ Também a reorganização das organizações que prestam cuidados de saúde em diferentes níveis oferece oportunidades de melhoria do sistema de saúde.4,5

Mas interessa explorar um pouco mais o papel que os pagamentos diretos dos cidadãos podem ter, dada a sensibilidade que normalmente acarretam esses pagamentos.

A utilização de pagamentos diretos por parte dos doentes tem (potencialmente) dois grandes efeitos, que são interdependentes: alteração da forma como os cidadãos utilizam o sistema de saúde e passar a responsabilidade de financiamento do SNS para o cidadão. O segundo destes dois efeitos não tem qualquer contribuição para os custos globais com cuidados de saúde, é apenas transferir custos de uns agentes para outros, mas reduzindo a proteção na doença e destruindo o valor económico correspondente.

Resta então saber se o primeiro efeito é suficientemente interessante para ser usado de forma abrangente. A resposta está dependente de como o comportamento de utilização de cuidados de saúde se altera com esses pagamentos, e se essa modificação de comportamento tem impacto, e qual a sua magnitude, nos custos com cuidados de saúde.

A redução do consumo de cuidados de saúde pode, ou não, contribuir para menores custos (ou menor ritmo de crescimento dos custos). Se levar a uma redução de cuidados de saúde desnecessários ou a uma reorientação para utilização mais apropriada de cuidados de saúde, contribuirá para a resolução do problema do crescimento nos custos de saúde.

Porém, se levar apenas a adiar uma utilização necessária, poderá acarretar custos mais elevados no futuro, agravando o problema. A importância de cada aspecto tem que ser determinada com recurso a análise da realidade, o que ainda não foi feito de forma sistemática para Portugal.

Para determinado tipo de cuidados, é razoável admitir que o ajustamento de comportamento será nulo (por exemplo, grandes intervenções cirúrgicas), enquanto noutras, como consultas, será mais fácil de encontrar um papel para esses pagamentos diretos.

Será improvável que apenas os eventuais ajustamentos decorrentes de pagamentos diretos (taxas moderado- ras e copagamentos) sejam suficientes para alterar a atual dinâmica de crescimento de custos de forma significativa. A necessidade de outras ações é, por isso, inquestionável. Assim, importa organizar e definir onde faz sentido intervir e que tipo de intervenções produz maiores efeitos para o esforço desenvolvido. Essas intervenções podem incidir sobre o lado da procura ou sobre o lado da oferta de cuidados de saúde.

\section{Custos, escolhas políticas e forças económicas}

A definição de um modelo de sustentabilidade financeira do Serviço Nacional de Saúde é, essencialmente, um modelo de acomodação dos custos do sector público com a saúde e do seu ritmo de crescimento.

$\mathrm{Na}$ medida em que as receitas do Serviço Nacional de Saúde são oriundas maioritariamente do Orçamento do Estado e que as verbas disponibilizadas ao SNS concorrem com outras aplicações de fundos dentro do sector público, há uma óbvia questão de escolha política entre utilizações alternativas ${ }^{6}$. Por exemplo, reduzir prestações de apoio social ou reduzir a actividade em educação pública será uma forma de rapidamente aumentar as verbas disponíveis para o Serviço Nacional de Saúde. Contudo, essas e outras aplicações das receitas do sector público têm também valor social, que um eventual crescimento relativo das despesas públicas em saúde tem que demonstrar que gera maior valor social que as utilizações alternativas.

Dado este aspecto, uma eventual 'solução' será estabelecer uma percentagem das receitas do Orçamento do Estado (ou dos impostos) como destinada ao Serviço Nacional de Saúde. Esta opção, porém, torna o orçamento do Serviço Nacional de Saúde, e logo os orçamentos das instituições que dele fazem parte, sensíveis à conjuntura económica de uma forma pró-cíclica - menores verbas em tempos de recessão, o que irá em sentido contrário ao que tradicionalmente se considera ser a evolução da necessidade de cuidados de saúde (mais pronunciada em tempos de crise).

Outra 'solução' é fixar um objectivo de despesa do Serviço Nacional de Saúde como percentagem do PIB. Embora aparentemente atrativa, tem dois problemas. O primeiro é partilhado com a 'solução' anterior: não acompanhar o ciclo das necessidades de saúde da população. O segundo problema é não acompanhar a evolução previsível de longo prazo para o peso das despesas com saúde na riqueza produzida na economia. Este é um efeito conhecido como doença de Baumol, em referência ao economista que primeiro o identificou. Este efeito aponta que sectores com elevada intervenção de recursos humanos, como são as actividades de prestação de cuidados de saúde terão, em média, menor crescimento da produtividade face a outros sectores de actividade económica. Os salários têm de evoluir de forma similar (para iguais qualificações) entre sectores de actividade, pois de outro modo a médio e longo prazo as escolhas de actividade profissional irão criar escassez relativa de mão-de-obra nos sectores com menores salários, fazendo-os subir. Significa então que é natural o 
peso dos sectores com muito trabalho intensivo aumentar apenas e unicamente por efeito de produtividade relativa. Para a despesa em cuidados de saúde do sector público permanecer constante, na presença deste efeito, terá que se verificar uma transferência de encargos do Estado para o utente, levando a um decréscimo efetivo de proteção pelo SNS. Não surge é uma 'solução' permanente.

Resta, então, a procura de soluções que atuem de forma mais direta sobre os custos do SNS. Os custos são, por definição, o resultado de somar para todas as actividades de prestação de cuidados de saúde o produto de quantidade por preço. Preço deve ser entendido de forma ampla, incluindo quer o preço de aquisição de bens e serviços fora do SNS quer o custo de o SNS providenciar diretamente o bem o serviço.

No imediato, é usualmente mais fácil atuar sobre o elemento preço para reduzir custos e a atual pressão no ajustamento das contas públicas em geral, decorrente do programa de assistência financeira internacional a Portugal, levaram à procura de soluções que tivessem capacidade de produzir resultados no curto prazo. ${ }^{7}$ Contudo, a médio prazo, a redução de preço tem limites, dado que são sempre necessários recursos para prestar cuidados de saúde. A contenção de custos no médio e longo prazo tem que forçosamente passar por uma intervenção sobre as 'quantidades'. Essa intervenção tem duas margens em que pode ocorrer. Por um lado, cada pessoa procurar menos cuidados de saúde por ter um estado de saúde melhor. Por outro lado, haver uma redução da abrangência do tipo de cuidados de saúde prestados pelo SNS. Destas duas margens possíveis, a mais interessante em termos de saúde e de

\section{REFERÊNCIAS}

1. Simões J, Barros PP, Machado S. Portugal: Health system review. Health Syst Transit. 2011;13:1-156.

2. Simões J, Barros PP, Pereira J, Organizadores. A Sustentabilidade financeira do Serviço Nacional de Saúde. Comissão para a Sustentabilidade Financeira do Serviço Nacional de Saúde. Lisboa: Edição Ministério da Saúde; 2008.

3. Barros PP. Inovação e sustentabilidade em saúde - Equação impossível? Cad Saúde Soc. 2011;1:99-113.

4. Fernandes V, Barros PP, Fernandes A. Três olhares sobre o futuro do sector da saúde. Lisboa: Ed. Princípia; 2011.

5. Barros PP, Fernandes V. Um ano depois da Troika na política custos é a primeira. A forma como o Serviço Nacional de Saúde se relaciona com o cidadão, a relação deste último com o médico (e com os profissionais de saúde em geral), e o modo como a sociedade encarar as escolhas sobre o sistema de saúde que pretende ter serão determinantes no evoluir do Serviço Nacional de Saúde. ${ }^{8}$

\section{CONCLUSÕES}

O controlo de custos com despesas públicas em saúde, o grande desafio atual do sistema de saúde português, não tem, uma única solução baseada em mecanismos de financiamento. Terá a prazo uma solução composta de muitas pequenas decisões, que promovam uma utilização adequada dos serviços e uma menor procura de cuidados de saúde por melhor saúde da população. Este último aspecto é de uma certa trivialidade em termos de discurso. $\mathrm{O}$ elemento não trivial está em o conseguir ligar à prática de uma forma descentralizada, com os instrumentos disponíveis, que são mais facilmente susceptíveis de influenciar a oferta de cuidados de saúde do que a sua procura. O perceber como instrumentos que atuem sobre a oferta de cuidados de saúde podem levar a uma adequado ajustamento da procura é um elemento chave da intervenção pública.

\section{CONFLITO DE INTERESSES}

O autor declara que não houve conflito de interesses na realização deste trabalho.

\section{FONTES DE FINANCIAMENTO}

O autor declara a inexistência de fontes de financiamento externas.

de saúde. Lisboa: Ed. Princípia; 2012.

6. Barros PP. Sentado à conversa sobre o Novo Contrato Social da Saúde. In: A Nova Saúde Pública: a saúde pública da era do conhecimento - Livro de Homenagem a Constantino Sakellarides. Lisboa: Gradiva; 2011. p 80-5.

7. Barros PP. Portugal: Memorando de Entendimento sobre políticas económicas e financeiras - Saúde. Brotéria. 2011;73:2738.

8. Barros PP. Pela sua Saúde. Colecção Ensaios. Lisboa: Fundação Francisco Manuel dos Santos; 2013. 